\title{
Damming a Molecular Energy Reservoir: Ion-regulated Electronic Energy Shuttling in a [2]Rotaxane.
}

\author{
Shilin $\mathrm{Yu}^{\dagger}{ }^{\dagger}$ Arkady Kupryakov, ${ }^{\ddagger}$ James E. M. Lewis, ${ }^{\S}{ }^{\dagger}$ Vicente Martí-Centelles, ${ }^{\dagger}$ Stephen M. \\ Goldup, ${ }^{*}$, Jean-Luc Pozzo, ${ }^{\dagger}$ Gediminas Jonusauskas, ${ }^{\ddagger}$ Nathan D. McClenaghan ${ }^{*} \dagger$ \\ ${ }^{\dagger}$ CNRS / University of Bordeaux, Institut des Sciences Moléculaires, Talence, France \\ ${ }^{\ddagger}$ CNRS / University of Bordeaux, Laboratoire Ondes et Matière d'Aquitaine, Talence, France \\ ${ }^{\S}$ School of Chemistry, University of Southampton, Highfield, Southampton SO17 1BJ, U.K.
}

\begin{abstract}
Bidirectional electronic energy shuttling is shown to occur between the molecular ring and axle components of a rotaxane. The engineered energetic and kinetic parameters give rise to long-lived, delayed luminescence. Perturbation of the quasiisoenergetic ring and stopper chromophore excited-state energy levels upon cation binding influences the energy shuttling process, and hence luminescence read-out, representing a new potential mechanism in luminescent molecular chemosensor development.
\end{abstract}

Luminescent rotaxanes ${ }^{i}$ in which the mechanical bond ${ }^{i i}$ between a linear axle and an encircling macrocycle alters the properties of a luminophore in either component have been developed for a range of purposes, including monitoring the relative co-conformation of the sub-units, iii sensing of guests bound within the cavity of the rotaxane, iv and improving the stability $^{v}$ and emission properties ${ }^{\mathrm{vi}}$ of the luminophore itself. Light has also been successfully used to promote processes in interlocked structures such as topological transformations, ${ }^{\text {vii }}$ dethreading/threading, ${ }^{\text {vii }}$ and shuttling. ${ }^{\text {ix }}$

The mechanical bond has also been used to study or optimize photophysical processes that rely on photo-induced electronic energy ${ }^{x}$ (e.g. quenching, FRET), or electron transfer ${ }^{x i}$ between chromophores by taking advantage of the fact that, although there is no covalent bond between the components of a rotaxane, they are unable to separate and their relative motions are highly circumscribed. Thus, through-bond processes are explicitly prevented, as no such bond exists, and although the chromophores are able to move relative to one another in defined ways thanks to the flexibility of the interlocked structure, they are prevented from diffusing apart.

In the current work, we sought to study reversible electronic energy transfer (REET) between matched chromophores to modulate rotaxane luminescence, as represented in Figure 1. REET processes have previously been observed between covalently linked chromophores $^{\text {xii }}$ but equivalent processes are challenging to observe between independent molecules in supramolecular assemblies due to the strong distance dependence of the REET phenomenon. The rotaxane scaffold serves as a suitable platform to study this relatively rare photochemical behaviour. Furthermore, we show that binding of a cation into the cavity of the macrocycle modulates the REET process and thus the luminescence response of the system. This allows the rotaxane to report the binding of zinc ions, suggesting that modulation of REET could be used as a new, luminescence lifetime-based reporting mode in molecular chemosensors.

The prerequisites for interchromophore REET, following photoexcitation, are that their lowest-lying energy levels are quasi-isoenergetic (within a few hundred $\mathrm{cm}^{-1}$ ) and that the kinetics for energy transfer should be faster than other major deexcitation processes. $^{\text {xii,xiii }}$ These conditions can be satisfied using combinations of transition metal complexes (microsecond excited-state lifetimes) and organic chromophores (millisecond excited-state triplet lifetimes), which allows ample time for bidirectional energy transfer to occur.

Thus, prototype bichromophoric rotaxane 1 (Figure 1) was designed with a pyrene-like chromophore on the ring component and a $\mathrm{Ru}(\mathrm{bpy})_{3}{ }^{2+}$-based chromophore (bpy $=2,2^{\circ}$ bipyridine) as a stopper component ${ }^{\text {xiv }}$ and prepared using an active template ${ }^{\mathrm{xv}} \mathrm{Cu}$-mediated azide-alkyne cycloaddition (AT-CuAAC) ${ }^{x v i}$ reaction between the corresponding pyrenefunctionalized bipyridine-containing macrocycle (Scheme S1), ${ }^{x i i}$ an acetylene functionalized $\mathrm{Ru}(\mathrm{bpy})_{3}{ }^{2+}$ complex, and an aryl azide (Scheme S2). Analogue 2 lacking the pyrene chromophore was prepared as a reference compound (Scheme S2) using a macrocycle lacking the pyrene substituent. 
(a)

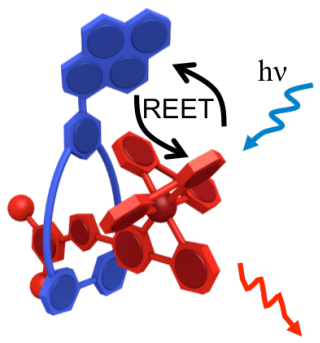

Delayed emission

(b)

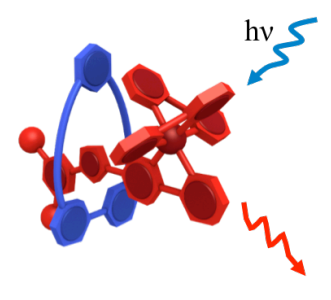

Emission

(c)

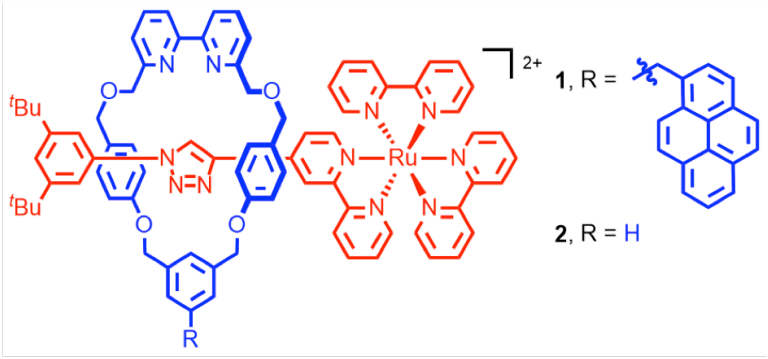

Figure 1. a) Cartoon showing origin of engineered delayed luminescence in bichromophoric [2]rotaxane 1; b) Luminescent process in simple pyrene-free rotaxane 2; c) Structural formulas of 1 and 2.

The electronic absorption spectrum of rotaxane 1 (Figure S1) contains the distinct absorption bands of both the pyrene and $\mathrm{Ru}(\mathrm{bpy})_{3}{ }^{2+}$ chromophores, indicating minimal ground-state electronic interaction. The MLCT absorption bands in the visible spectral region in 1 and 2 are identical, as is the red room temperature MLCT-based emission ( $\lambda_{\text {emmax }}=620 \mathrm{~nm}$, $\lambda_{\mathrm{ex}}=450 \mathrm{~nm}, \Phi=0.11$ for both) in degassed acetonitrile (Figure S2). A small energy difference $\left(\Delta \mathrm{E}=515 \mathrm{~cm}^{-1}\right.$ ) between the lowest-lying triplets of the two chromophores in rotaxane 1 , as required for REET, was estimated as the difference between the highest energy MLCT and pyrene features in $77 \mathrm{~K}$ phosphorescence spectra (Figure S3).

Despite the similar emission spectra, enhanced oxygen sensitivity was observed for 1 compared with $2\left(\Phi_{\text {deoxy }} / \Phi_{\text {oxy }}=18.3\right.$ vs $\left.\Phi_{\text {deoxy }} / \Phi_{\text {oxy }}=5.0\right)$. This is consistent with enhanced bimolecular quenching by dissolved oxygen in the case of 1 being favoured by a prolonged excited-state lifetime, as confirmed by microsecond luminescence decays, $\tau=9.75 \mu \mathrm{s}$ vs. $\tau=1.2 \mu \mathrm{s}$ for 1 and $\mathbf{2}$, respectively (Figure 2). Analysis of luminescence decays on shorter timescales at $300 \mathrm{~K}$ (Figure S4) showed an additional ca. $15 \mathrm{~ns}$ decay component in the case of 1 but not 2. This additional fast decay corresponds to the time required for energy to be repartitioned between the two chromophores of 1 via REET, resulting in a thermallyequilibrated excited system, whose deexcitation corresponds to the slow component.

Direct and unambiguous evidence for the formation of an exited-state equilibrium as a result of energy shuttling between ring and stopper was sought by transient absorption spectroscopy (Figure 3). Selective excitation in the MLCT band of the $\mathrm{Ru}^{2+}$-complex stopper of 1 revealed an initial negative visible ground state-bleaching band (and positive signature at $370 \mathrm{~nm}$ ) which evolves synchronously with the growth of a positive band $(410 \mathrm{~nm})$ ascribed to the pyrene $T_{n} \leftarrow T_{1}$ transient with a time constant similar to that of the prompt luminescence decay component (see Figure S5 for kinetic analysis). This corresponds to the real-time observation of energy being redistributed between the rotaxane ring and dumbbell chromophores, with a rate which is the sum of forward $\left(k_{f}\right)$ and back $\left(k_{b}\right)$ interchromophore energy transfer rates. ${ }^{\text {xiii }}$ 


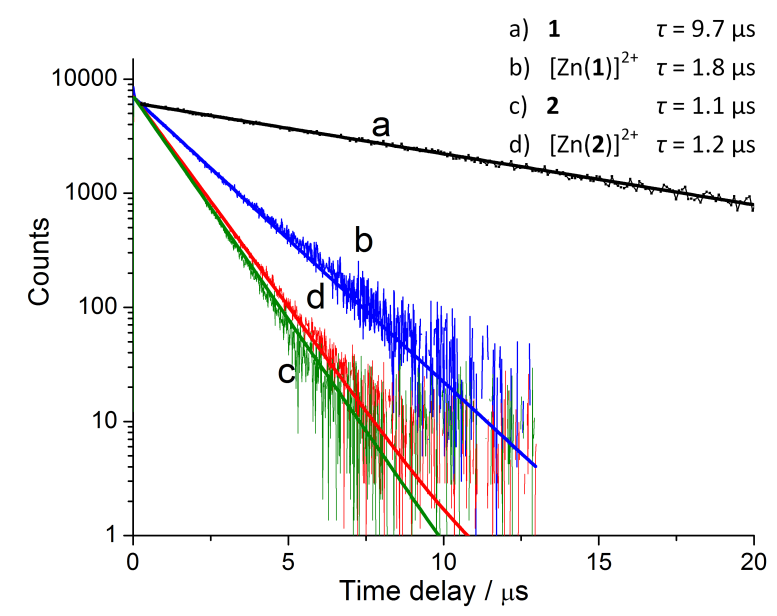

Figure 2. Luminescence decays of rotaxanes $1,[\mathrm{Zn}(\mathbf{1})]^{2+}, 2$ and $[\mathrm{Zn}(\mathbf{2})]^{2+}$ in degassed acetonitrile $\left(\lambda_{\mathrm{ex}}=450 \mathrm{~nm}, \lambda_{\mathrm{em}}=620 \mathrm{~nm}\right)$.

After the initial energy redistribution between ring and stopper chromophores, the concomitant decay of the transient signals associated with pyrene triplet and MLCT transient unambiguously confirmed that a dynamic excited-state equilibrium had been established, which is a result of reversible electronic energy transfer within rotaxane 1.

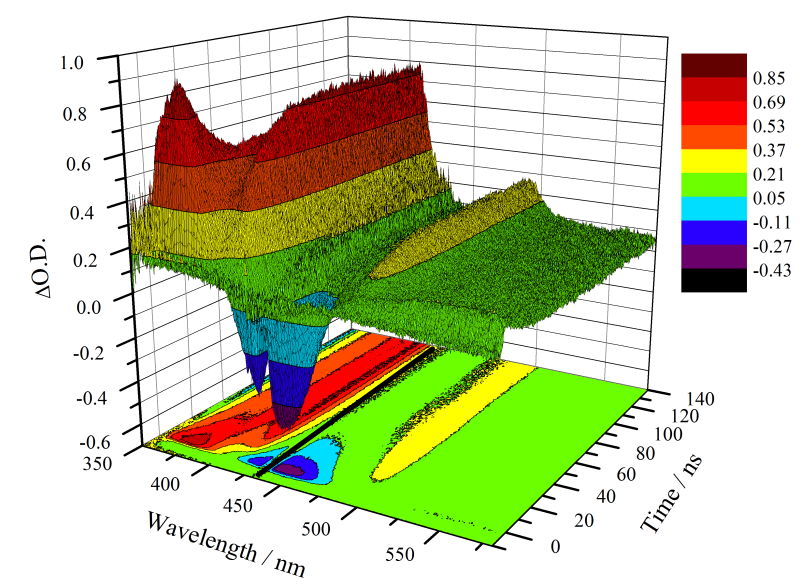

Figure 3. Transient absorption map showing excitation energy redistributing between pyrene and $\mathrm{Ru}(\mathrm{bpy})_{3}{ }^{2+}$ in 1 in $\mathrm{CH}_{3} \mathrm{CN}\left(\lambda_{\mathrm{ex}}=450 \mathrm{~nm}\right)$ at $300 \mathrm{~K}$. Note: Artefact at $442 \mathrm{~nm}$ is due to notch filter blocking parasite laser excitation.

The dynamic behaviour of excited rotaxane 1 , which is governed by both interacting dumbell and stopper components, was mathematically modelled and described by a set of differential equations (SI) and may further be rationalised by Equation 1. Here $\alpha$ and $(1-\alpha)$ correspond to the relative populations of the excited ring and axle chromophores at equilibrium, respectively. Using this notation, $(1-\alpha) / \alpha$ equates to the excited-state equilibrium constant, $K_{e q}$.

$$
\frac{1}{\tau_{\text {rotaxane }}}=(1-\alpha) \cdot\left(\frac{1}{\tau_{\text {thread }}}\right)+\alpha\left(\frac{1}{\tau_{\text {ring }}}\right) \quad \text { eq. } 1
$$


Analysis of variable temperature spectroscopic data (see $\mathrm{SI}$ ) afforded a triplet-triplet energy gap of $475 \mathrm{~cm}^{-1}$, similar to the value obtained from the low temperature phosphorescence data $\left(515 \mathrm{~cm}^{-1}\right)$ and the population of each excited state at equilibrium as a function of temperature, which was also determined through kinetic analysis. At equilibrium at $298 \mathrm{~K}$, the excitation energy is predominantly localized on the ring pyrene unit $(81 \%)$ compared with the inorganic stopper (19\%), giving a $K_{e q}$ of ca. 4 . Furthermore, the rate of the back transfer (from ring to stopper) and forward (stopper to ring) transfer can be calculated $\left(7.07 \times 10^{7} \mathrm{~s}^{-1}\right.$ vs $5.36 \times 10^{8} \mathrm{~s}^{-1}$, respectively).

Having demonstrated that REET occurs efficiently in rotaxane 1, we turned our attention to how this process might be manipulated using the properties of the interlocked structure. Previously, rotaxanes bearing cavities structurally similar to those of rotaxanes $\mathbf{1}$ and $\mathbf{2}$ were shown to bind first row transition metal ions in a 1:1 stoichiometry in a mechanically chelating fashion involving the bipyridine unit and the triazole, ${ }^{\text {xvii }}$ The triazole unit of $\mathbf{1}$ is directly conjugated to the $\mathrm{Ru}(\mathrm{bpy}){ }_{3}{ }^{2+}$ chromophore, and thus coordination of an ion such as $\mathrm{Zn}^{2+}$ in the cavity of the rotaxane is expected to stabilize the MLCT state by rendering the ligand more electron deficient. Given that even slight modification of the ${ }^{3} \mathrm{MLCT}$ energy level with respect to that of the pyrene (which is largely insensitive to the medium) would perturb and potentially interrupt the REET process with an accompanying effect on luminescence lifetime, we embarked on a proof-of-principle demonstration of lifetime-based luminescent sensors based on analyte-induced perturbation of bidirectional electronic energy transfer. Such a technique may have interest in time-gated detection and sensor concentrationindependent measurements.

${ }^{1} \mathrm{H}$-NMR analysis (Figure S7) of rotaxane 1 in the absence or presence of $\mathrm{Zn}^{2+}$ revealed differences consistent with binding of the metal ion in the rotaxane cavity; several resonances were seen to shift, notably the triazole $\mathrm{C}-\mathrm{H}$ and the central proton of the resorcinol moiety of the macrocycle. Spectrophotometric titrations of rotaxane 1 with $\mathrm{Zn}\left(\mathrm{ClO}_{4}\right)_{2} \cdot 6 \mathrm{H}_{2} \mathrm{O}$ (Figure S8) were carried out to further investigate ion binding and obtain binding constants. On adding $\mathrm{Zn}^{2+}$, the MLCT absorption bands $(400-500 \mathrm{~nm})$ became slightly less intense and broader. Several isosbestic points $(477 \mathrm{~nm}, 374 \mathrm{~nm}$ and $325 \mathrm{~nm}$ ) along with the Job plot (Figure S9) point to a $1: 1$ stoichiometry for $\mathrm{Zn}^{2+}$ binding by 1 . Binding constants on the same order of magnitude were obtained for rotaxane 1 and $2\left(1.15 \pm 0.2 \times 10^{6} \mathrm{M}^{-1}\right.$ and $7.14 \pm 2.6 \times 10^{6} \mathrm{M}^{-1}$, respectively), as they integrate structurally-similar binding cavities (Figure S10).

More striking ion-induced changes were observed in the luminescence spectra. The luminescence band maximum of $1\left(\mathrm{CH}_{3} \mathrm{CN}, \lambda_{\mathrm{ex}}=475 \mathrm{~nm}\right.$, air-equilibrated) shifts on adding $\mathrm{Zn}^{2+}$ from $626 \mathrm{~nm}$ to $649 \mathrm{~nm}\left(\Delta \omega=705 \mathrm{~cm}^{-1}\right)$ and the emission intensity increases $\left(\Phi\left([\mathrm{Zn}(1)]^{2+}\right) / \Phi(1)=5\right.$, Figure 4$)$. In the case of rotaxane $2, \mathrm{Zn}^{2+}$ coordination gives rise to a similar shift in the emission maxima, but with a smaller luminescence enhancement $\left(\Phi\left([\operatorname{Zn}(2)]^{2+}\right) / \Phi(2)=1.5\right.$, Figure $\left.\mathrm{S} 10\right)$. The dramatically enhanced luminescence efficiency of rotaxane 1 in the presence of $\mathrm{Zn}^{2+}$ is consistent with an ion-induced disruption of energy shuttling between the stopper and macrocycle chromophores as, if this process is rendered less efficient, the lifetime of the emission is shortened and quenching by ambient oxygen is reduced, resulting in luminescence turn "on". Luminescence decay analysis supports this hypothesis as the delayed luminescence lifetime components of rotaxanes $\mathbf{1}$ and $\mathbf{2}$ in degassed solution in the presence 5 eq. $\mathrm{Zn}^{2+}$ are, respectively, $1.8 \mu \mathrm{s}$ and $1.2 \mu \mathrm{s}$ versus $9.75 \mu$ s and $1.1 \mu$ s for 1 and 2 alone (Figure 2). 


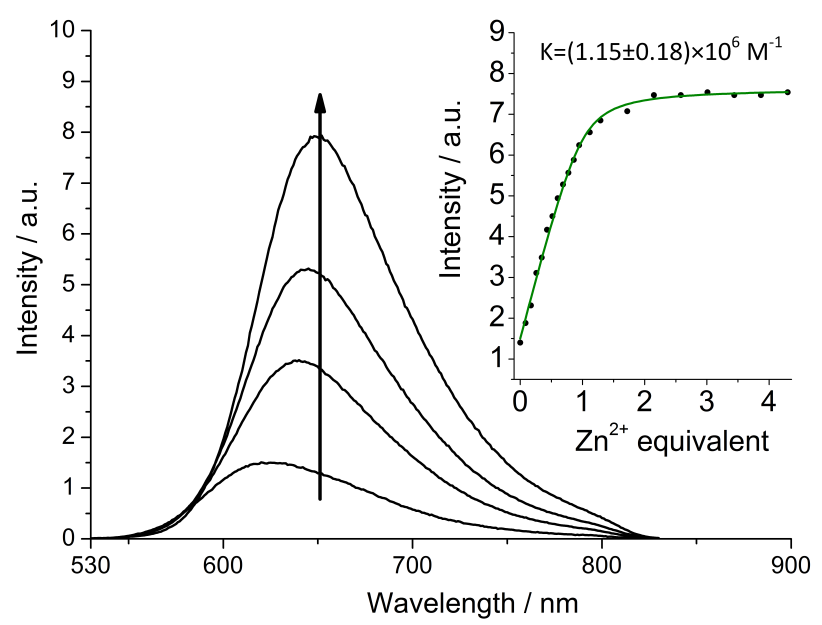

Figure 4. Luminescence spectra $\left(\lambda_{\mathrm{ex}}=475 \mathrm{~nm}\right)$ of 1 on adding $\mathrm{Zn}\left(\mathrm{ClO}_{4}\right)_{2}$ in air equilibrated acetonitrile showing ion-regulated oxygen sensitivity. (No. of equivalents of $\mathrm{Zn}^{2+}$ in order of increasing emission intensity at $650 \mathrm{~nm}: 0,0.4,0.8,4.5)$. Inset: Changing emission intensity $(\lambda=640 \mathrm{~nm})$ on adding $\mathrm{Zn}^{2+}$.

The transient absorption map of excited $[\mathrm{Zn}(\mathbf{1})]^{2+}$ shows several qualitatively similar features to that of 1 (see Figure S12 and kinetic analysis in Figure S13). However, after the initial relaxation $(\tau=13 \mathrm{~ns})$, a much greater degree of excitation energy is localised on the inorganic unit $(67 \%$ versus $19 \%$ for 1$)$. This demonstrates that the excited-state equilibrium is significantly perturbed by ion binding, which is reflected in a luminescence lifetime modulation and increased emission intensity in oxygenated solution as a consequence of decreased oxygen sensitivity. Indeed, binding of $\mathrm{Zn}^{2+}$ stabilizes/lowers the ${ }^{3} \mathrm{MLCT}$ state energy by ca. $700 \mathrm{~cm}^{-1}$ with respect to the unchanging pyrene triplet states, thus decreasing the proportion of energy that is temporarily stored on the pyrene group. Figure 5 summarises the ensemble of pertinent low-lying states, relative energies and the rates of ring-stopper energy transfer processes in 1 compared with $[\mathrm{Zn}(\mathbf{1})]^{2+}$.
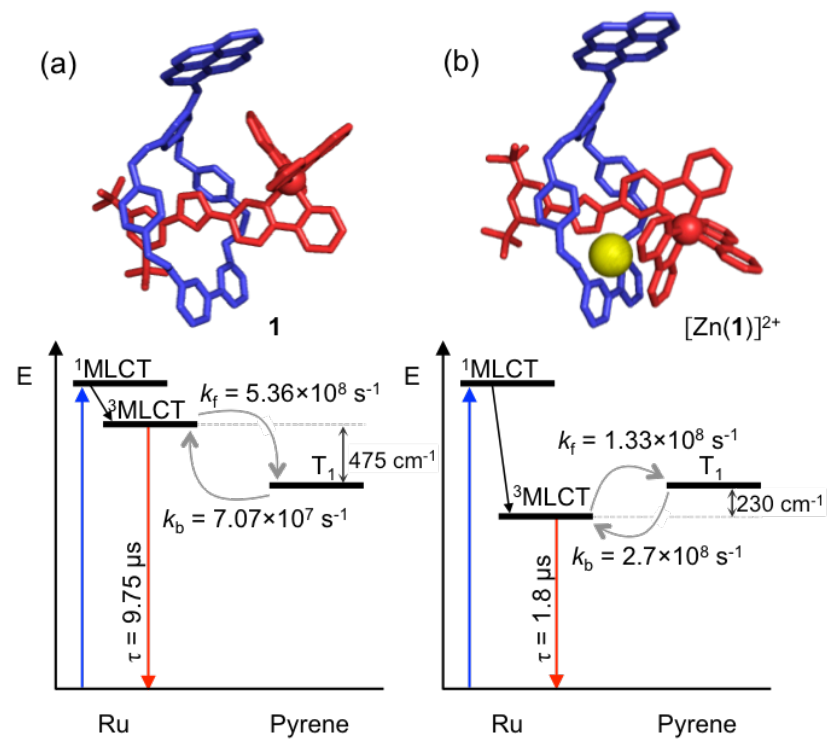

Figure 5. Jablonski-Perrin diagram representing pertinent low lying excited states and electronic energy transfer between ${ }^{3} \mathrm{MLCT}$ and triplet pyrene of rotaxanes 1 (a) and $[\mathrm{Zn}(1)]^{2+}$ (b) at $300 \mathrm{~K}$. Molecular modelling of rotaxane structures used Spartan'18 - MMFF force field. ${ }^{\text {xix }}$

Finally, as might be expected from the above discussion, the analogous titration of 1 with $\mathrm{Zn}^{2+}$ in degassed solution is somewhat different from that obtained under oxygenated conditions (Figure S11). The steady-state emission intensity of 1 varies much less on adding 
$\mathrm{Zn}^{2+}$ (ratio 1:1.4) and an isoemissive point $(616 \mathrm{~nm})$ is observed. Thus, whereas under oxygenated conditions rotaxane 1 reports the binding of $\mathrm{Zn}^{2+}$ in a "switch on" manner, under deoxygenated conditions the rotaxane host facilitates ratiometric detection of $\mathrm{Zn}^{2+}$ by monitoring unchanging emission intensity $(616 \mathrm{~nm})$ versus significant MLCT changes at, for example, $645 \mathrm{~nm}$, making detection largely rotaxane concentration independent.

In conclusion, integrating energetically and kinetically matched chromophores onto ring and stopper units is shown to offer a design principle to enable fast reversible intercomponent energy exchange to take place within a rotaxane. Instilling this reversible electronic energy transfer process into a rotaxane is shown to efficiently result in delayed luminescence and long luminescence lifetime. Furthermore, the high sensitivity of this energy shuttling to perturbation of the relative energies of the excited states involved in the REET process was used to develop a simple chemosensor with the potential for ratiometric detection of metal ions. On-going work in studies of coupled ring and energy shuttling and developing a new approach to lifetime-based chemosensing will be reported in due course.

\section{AUTHOR INFORMATION}

\section{Corresponding Author}

* nathan.mcclenaghan@u-bordeaux.fr

*s.goldup@soton.ac.uk

\section{Present Addresses}

Department of Chemistry, Imperial College London, Molecular Sciences Research Hub, 80 Wood Lane, London W12 0BZ, UK.

\section{Funding Sources}

Agence Nationale de la Recherche [grant number ANR-16-CE29-0011], China Scholarship Council, European Union's Horizon 2020 research and innovation programme under the Marie Skłodowska-Curie grant agreements: No. 796612 (V. M-C.) \& No. 660731 (J.E.M.L.), CNRS.

No competing financial interests have been declared.

\section{ACKNOWLEDGMENT}

We thank the analytical facilities CESAMO (NMR and MS) of the Institut des Sciences Moléculaires, University of Bordeaux as well as aforementioned funding sources.

\section{REFERENCES}

(i) For recent reviews see: (a) Ma, X.; Tian, H., Bright Functional Rotaxanes. Chem. Soc. Rev. 2010, 39, 70-80. (b) Qu, D. H.; Wang, Q. C.; Zhang, Q. W.; Ma, X.; Tian, H., Photoresponsive Host-Guest Functional Systems. Chem. Rev. 2015, 115, 7543-7588. (c) Yu, S.; McClenaghan, N. D.; Pozzo, J.-L. Photochromic Rotaxanes and Pseudorotaxanes. Photochem. Photobiol. Sci. 2019, 18, 2102-2111. (d) Corra, S.; Curcio, M.; Baroncini, M.; Silvi, S.; Credi, A. Photoactivated Artificial Molecular Machines that Can Perform Tasks Adv. Mater., 2020, 32, 1906064.

(ii) Selected reviews on the synthesis and properties of MIMs: (a) Beves, J. E.; Blight, B. A.; Campbell, C. J.; Leigh, D. A.; McBurney, R. T., Strategies and Tactics for the Metal-Directed Synthesis of Rotaxanes, Knots, Catenanes, and Higher Order Links. Angew. Chem. Int. Ed. 2011, 50, 9260-9327. (b) Xue, M.; Yang, Y.; Chi, X.; Yan, X.; Huang, F., Development of Pseudorotaxanes and Rotaxanes: From Synthesis to Stimuli-Responsive Motions to Applications. Chem. Rev. 2015, 115, 7398-7501. (c) Bruns, C. J.; Stoddart, J. F., The Nature of the Mechanical Bond: From Molecules to Machines. Wiley: 2016. (d) Hou, X.; Ke, C.; Fraser Stoddart, J., Cooperative Capture Synthesis: Yet Another Playground for Copper-Free Click Chemistry. Chem. Soc. Rev. 2016, 45, 3766-3780. (d) Lewis, J. E. M.; Beer, P. D.; Loeb, S. J.; Goldup, S. M., Metal Ions in the Synthesis of Interlocked Molecules and Materials. Chem. Soc. Rev. 2017, 46, 2577-2591. (e) Maynard, J. R. J.; Goldup, S. M., Strategies for the Synthesis of Enantiopure Mechanically Chiral Molecules. Chem 2020, 6, 1914-1932.

(iii) (a) Zhou, W.; Li, J.; He, X.; Li, C.; Lv, J.; Li, Y.; Wang, S.; Liu, H.; Zhu, D. A Molecular Shuttle for Driving a Multilevel Fluorescence Switch. Chem. Eur. J. 2008, 14, 754-763. (b) Wang, W.-K.; Xu, Z.-Y.; Zhang, Y.-C.; Wang, H.; Zhang, D.-W.; Liu, Y.; Li, Z.-T. A Tristable [2]Rotaxane That Is Doubly Gated by Foldamer and Azobenzene Kinetic Barriers. Chem. Commun. 2016, 52, 7490-7493. (c) Ma, X.; Zhang, J.; Cao, J.; Yao, X.; Cao, T.; Gong, Y.; Zhao, C.; Tian, H., A Room Temperature Phosphorescence Encoding [2]Rotaxane Molecular Shuttle. Chem. Sci. 2016, 7, 4582-4588. (d) Sagara, Y.; Karman, M.; 
Verde-Sesto, E.; Matsuo, K.; Kim, Y.; Tamaoki, N.; Weder, C., Rotaxanes as Mechanochromic Fluorescent Force Transducers in Polymers. J. Am. Chem. Soc. 2018, 140, 1584-1587. (e) David, A. H. G.; Casares, R.; Cuerva, J. M.; Campana, A. G.; Blanco, V., A [2]Rotaxane-Based Circularly Polarized Luminescence Switch. J. Am. Chem. Soc. 2019, 141, 18064-18074.

(iv) Selected examples and reviews: (a) Ma, X.; Tian, H., Bright Functional Rotaxanes. Chem. Soc. Rev. 2010, 39, 70-80. (b) Lim, J. Y. C.; Marques, I.; Felix, V.; Beer, P. D., Enantioselective Anion Recognition by Chiral Halogen-Bonding [2]Rotaxanes. J. Am. Chem. Soc. 2017, 139, 12228-12239. (c) Denis, M.; Pancholi, J.; Jobe, K.; Watkinson, M.; Goldup, S. M., Chelating Rotaxane Ligands as Fluorescent Sensors for Metal lons. Angew. Chem. Int. Ed. 2018, 57, 5310-5314. (d) Lim, J. Y. C.; Marques, I.; Felix, V.; Beer, P. D., A Chiral Halogen-Bonding [3]Rotaxane for the Recognition and Sensing of Biologically Relevant Dicarboxylate Anions. Angew. Chem. Int. Ed. 2018, 57, 584-588. (e) Denis, M.; Qin, L.; Turner, P.; Jolliffe, K. A.; Goldup, S. M., A Fluorescent Ditopic Rotaxane lon-Pair Host. Angew. Chem. Int. Ed. 2018, 57, 5315-5319. (f) Bąk, K. M.; Porfyrakis, K.; Davis, J. J.; Beer, P. D., Exploiting the Mechanical Bond for Molecular Recognition and Sensing of Charged Species. Mater. Chem. Front. 2020, 4, 1052-1073. (g) Knighton, R. C.; Dapin, S.; Beer, P. D., Luminescent Anion Sensing by Transition-Metal Dipyridylbenzene Complexes Incorporated into Acyclic, Macrocyclic and Interlocked Hosts. Chem. Eur. J. 2020, 26, 5288-5296.

(v) Selected examples: (a) Buston, J. E. H.; Young, J. R.; Anderson, H. L., Rotaxane-Encapsulated Cyanine Dyes: Enhanced Fluorescence Efficiency and Photostability. Chem. Commun. 2000, 905-906. (b) Gassensmith, J. J.; Baumes, J. M.; Smith, B. D., Discovery and Early Development of Squaraine Rotaxanes. Chem. Commun. 2009, 6329-6338. (c) Baumes, J. M.; Gassensmith, J. J.; Giblin, J.; Lee, J. J.; White, A. G.; Culligan, W. J.; Leevy, W. M.; Kuno, M.; Smith, B. D., Storable, Thermally Activated, near-Infrared Chemiluminescent Dyes and Dye-Stained Microparticles for Optical Imaging. Nat. Chem. 2010, 2, 1025-1030. (d) Masai, H.; Terao, J.; Seki, S.; Nakashima, S.; Kiguchi, M.; Okoshi, K.; Fujihara, T.; Tsuji, Y., Synthesis of One-Dimensional Metal-Containing Insulated Molecular Wire with Versatile Properties Directed toward Molecular Electronics Materials. J. Am. Chem. Soc. 2014, 136, 1742-1745. (e) Masai, H.; Terao, J., Synthetic Methodologies for Structurally Defined Linked-[N]Rotaxanes with Permethylated Cyclodextrins: Platform for Functionalized Molecular Electronics. Bull. Chem. Soc. Jpn. 2019, 92, 529-539. (f) Zhang, Z.; Tizzard, G. J.; Williams, J. A. G.; Goldup, S. M., Rotaxane PtiiComplexes: Mechanical Bonding for Chemically Robust Luminophores and Stimuli Responsive Behaviour. Chem. Sci. 2020, 11, 1839-1847.

(vi) Selected examples: (a) Inouye, M.; Hayashi, K.; Yonenaga, Y.; Itou, T.; Fujimoto, K.; Uchida, T. A.; Iwamura, M.; Nozaki, K., A Doubly Alkynylpyrene-Threaded [4]Rotaxane That Exhibits Strong Circularly Polarized Luminescence from the Spatially Restricted Excimer. Angew. Chem. Int. Ed. 2014, 53, 1439214396. (b) Hou, X.; Ke, C.; Bruns, C. J.; McGonigal, P. R.; Pettman, R. B.; Stoddart, J. F., Tunable Solid-State Fluorescent Materials for Supramolecular Encryption. Nat. Commun. 2015, 6, 6884. (c) Hayashi, K.; Miyaoka, Y.; Ohishi, Y.; Uchida, T. A.; Iwamura, M.; Nozaki, K.; Inouye, M., Observation of Circularly Polarized Luminescence of the Excimer from Two Perylene Cores in the Form of [4]Rotaxane. Chem. Eur. J. 2018, 24, 14613-14616. (d) Garci, A.; Beldjoudi, Y.; Kodaimati, M. S.; Hornick, J. E.; Nguyen, M. T.; Cetin, M. M.; Stern, C. L.; Roy, I.; Weiss, E. A.; Stoddart, J. F., Mechanical-BondInduced Exciplex Fluorescence in an Anthracene-Based Homo[2]Catenane. J. Am. Chem. Soc. 2020, 142, 7956-7967.

(vii) (a) Tron, A.; Jacquot de Rouville, H.-P.; Ducrot, A.; Tucker, J. H. R.; Baroncini, M.; Credi, A.; McClenaghan, N. D. Photodriven [2]Rotaxane-[2]Catenane Interconversion. Chem. Commun. 2015, 51, 2810-2813. (b) Tron, A.; Thornton, P. J.; Lincheneau, C.; Desvergne, J.-P.; Spencer, N.; Tucker, J. H. R.; McClenaghan, N. D. Reversible Photocapture of a [2]Rotaxane Harnessing a Barbiturate Template. J. Org. Chem. 2015, 80, 988-996. (c) Wan, P.; Jiang, Y.; Wang, Y.; Wang, Z.; Zhang, X. Tuning Surface Wettability through Photocontrolled Reversible Molecular Shuttle. Chem. Commun. 2008, 5710-5712.

(viii ) (a) Guo, Q.-H.; Qiu, Y.; Kuang, X.; Liang, J.; Feng, Y.; Zhang, L.; Jiao, Y.; Shen, D.; Astumian, R. D.; Stoddart, J. F. Artificial molecular pump operating in response to electricity and light. J. Am. Chem. Soc. 2020, 142, 14443-14449. (b) Scarpantonio, L.; Tron, A.; Destribats, C.; Godard, P.; McClenaghan, N. D. Concatenation of Reversible Electronic Energy Transfer and Photoinduced Electron Transfer to Control a Molecular Piston. Chem. Commun. 2012, 48, 3981-3983. (c) Yu, G.; Han, C.; Zhang, Z.; Chen, J.; Yan, X.; Zheng, B.; Liu, S.; Huang, F.-H. Pillar[6]arene-Based Photoresponsive Host-Guest Complexation. J. Am. Chem. Soc. 2012, 134, 8711-8717.

(ix) Selected examples: (a) Gatti, F. G.; Leon, S.; Wong, J. K.; Bottari, G.; Altieri, A.; Morales, M. A.; Teat, S. J.; Frochot, C.; Leigh, D. A.; Brouwer, A. M.; Zerbetto, F., Photoisomerization of a Rotaxane Hydrogen Bonding Template: Light-Induced Acceleration of a Large Amplitude Rotational Motion. Proc Natl Acad Sci U S A 2003, 100, 10-14. (b) Perez, E. M.; Dryden, D. T.; Leigh, D. A.; Teobaldi, G.; Zerbetto, F., A Generic Basis for Some Simple Light-Operated Mechanical Molecular Machines. J. Am. Chem. Soc. 2004, 126, 12210-12211. (c) Wang, Q. C.; Qu, D. H.; Ren, J.; Chen, K.; Tian, H., A Lockable Light-Driven Molecular Shuttle with a Fluorescent Signal. Angew. Chem. Int. Ed. 2004, 43, 2661-2665. (d) Zhou, W.; Chen, D.; Li, J.; Xu, J.; Lv, J.; Liu, H.; Li, Y.-L. Photoisomerization of Spiropyran for Driving a Molecular Shuttle. Org. Lett. 2007, 9, 3929-3932. (e) Colasson, B.; Credi, A.; Ragazzon, G. Light-driven molecular machines based on ruthenium(II) polypyridine complexes: Strategies and recent advances. Coord. Chem. Rev. 2016, 325, 125-134. (f) Martinez-Cuezva, A.; 
Saura-Sanmartin, A.; Nicolas-Garcia, T.; Navarro, C.; Orenes, R.; Alajarina, M.; Berna, J. Photoswitchable Interlocked Thiodiglycolamide as a Cocatalyst of a Chalcogeno-Baylis-Hillman Reaction. Chem. Sci. 2017, 8, 3775-3780.

(x) Selected examples: (a) Ogoshi, T.; Yamafuji, D.; Yamagishi, T.; Brouwer, A. M. Forster Resonance Energy Transfer by Formation of a Mechanically Interlocked [2]Rotaxane. Chem. Commun. 2013, 49 5468-5470. (b) Kirner, S.; Henkel, C.; Guldi, D. M.; Megiatto, J. D.; Schuster, D. I. Multistep Energy and Electron Transfer Processes in Novel Rotaxane Donor-Acceptor Hybrids Generating Microsecond-Lived Charge Separated States. Chem. Sci. 2015, 6, 7293-7304. (c) Movsisyan, L. D.; Peeks, M. D.; Greetham, G. M.; Towrie, M.; Thompson, A. L.; Parker, A. W.; Anderson, H. L. Photophysics of Threaded sp-Carbon Chains: The Polyyne is a Sink for Singlet and Triplet Excitation. J. Am. Chem. Soc. 2014, 136, 17996-18008. (d) Fu, H.-G.; Zhang, H.-Y.; Zhang, H.-Y.; Liu, Y. Photo-Controlled Chirality Transfer and FRET Effects based on Pseudo[3]Rotaxane. Chem. Commun. 2019, 55, 13462-13465. (e) Pruchyathamkorn, J.; Kendrick, W. J.; Frawley, A. T.; Mattioni, A.; Caycedo-Soler, F.; Huelga, S. F.; Plenio, M. B.; Anderson, H. L., A Complex Comprising a Cyanine Dye Rotaxane and a Porphyrin Nanoring as a Model Light-Harvesting System. Angew. Chem. Int. Ed. 2020.

(xi) (a) Ashton, P. R.; Ballardini, R.; Balzani, V.; Credi, A.; Dress, K. R.; Ishow, E.; Kleverlaan, C. J.; Kocian, O.; Preece, J. A.; Spencer, N. A Photochemically Driven Molecular-Level Abacus. Chem. Eur.J. 2000, 6, 3558-3574. (b) Brouwer. A. M.; Frochot, C.; Gatti, F. G.; Leigh, D. A.; Mottier, L.; Paolucci, F.; Roffia, S.; Wurpel, G. W. H. Photoinduction of Fast, Reversible Translational Motion in a HydrogenBonded Molecular Shuttle. Science 2001, 291 (5511), 2124-2128. (c) Colasson, B.; Credi, A.; Ventura, B. Photoinduced Electron Transfer Involving a Naphthalimide Chromophore in Switchable and Flexible [2]Rotaxanes. Chem. Eur. J. 2020, 26, 534-542. (d) Kumpulainen, T.; Panman, M.R.; Bakker, B.H.; Hilbers, M.; Woutersen, S.; Brouwer, A.M. Accelerating the Shuttling in Hydrogen-Bonded Rotaxanes: Active Role of the Axle and the End Station. J. Am. Chem. Soc. 2019, 141, 19118-19129. (e) Jia, F.; Schroder, H. V.; Yang, L.-P.; von Essen, C.; Sobottka, S.; Sarkar, B.; Rissanen, K.; Jiang, W.; Schalley, C. A. Redox-Responsive Host-Guest Chemistry of a Flexible Cage with Naphthalene Walls. J. Am. Chem. Soc. 2020, 142, 3306-3310.

(xii ) (a) Denisov, S. A.; Yu, S.; Jonusauskas, G.; Pozzo, J.-L.; McClenaghan, N. D. Harnessing Reversible Electronic Energy Transfer: From Molecular Dyads to Molecular Machines. ChemPhysChem 2016, 17, 1794-1804; (b) Wang, X.Y.; Del Guerzo, A; Schmehl, R.H. Photophysical behavior of transition metal complexes having interacting ligand localized and metal-to-ligand charge transfer states. J. Photochem. Photobiol. C. Photochem Rev. 2004, 5, 55-77.

(xiii ) Ford, W. E.; Rodgers, M. A. J. Reversible Triplet-Triplet Energy Transfer within a Covalently Linked Bichromophoric Molecule. J. Phys. Chem. 1992, 96, 2917-2920.

(xiv) For examples of other matched pairs see: (a) Yonemoto, D.T.; Papa, C.M.; Mongin, C.; Castellano, F.N. Thermally Activated Delayed Photoluminescence: Deterministic Control of Excited-State Decay. J. Am. Chem. Soc. 2020, 142, 10883-10893; (b) Denisov, S.; Cudré, Y.; Verwilst, P.; Jonusauskas, G.; Marín-Suárez, M.; Fernandez-Sanchez, J.; Baranoff, E.; McClenaghan N. D. Direct Observation of Reversible Electronic Energy Transfer Involving an Iridium Center. Inorg. Chem. 2014, 53, 2677-2682.

(xv) (a) Crowley, J. D.; Goldup, S. M.; Lee, A.-L.; Leigh, D. A.; McBurney, R. T. Active Metal Template Synthesis of Rotaxanes, Catenanes and Molecular Shuttles. Chem. Soc. Rev. 2009, 38, 1530-1541. (b) Denis, M.; Goldup, S. M. The Active Template Approach to Interlocked Molecules. Nat. Rev. Chem. 2017, 1, 0061.

(xvi) Selected examples: (a) Aucagne, V.; Hanni, K. D.; Leigh, D. A.; Lusby, P. J.; Walker, D. B., Catalytic "Click" Rotaxanes: A Substoichiometric Metal-Template Pathway to Mechanically Interlocked Architectures. J. Am. Chem. Soc. 2006, 128, 2186-2187. (b) Lahlali, H.; Jobe, K.; Watkinson, M.; Goldup, S. M., Macrocycle Size Matters: "Small" Functionalized Rotaxanes in Excellent Yield Using the Cuaac Active Template Approach. Angew. Chem. Int. Ed. 2011, 50, 4151-4155. (c) Noor, A.; Lo, W. K. C.; Moratti, S. C.; Crowley, J. D. CuAAC "Click" Active-Template Synthesis of Functionalised [2]Rotaxanes Using Small exo-Substituted Macrocycles: How Small is Too Small? Chem. Commun. 2014, 50, 7044-7047. (d) Langton, M. J.; Xiong, Y.; Beer, P. D., Active-Metal Template Synthesis of a Halogen-Bonding Rotaxane for Anion Recognition. Chem. Eur. J. 2015, 21, 18910-18914. (e) Lewis, J. E. M.; Winn, J.; Cera, L.; Goldup S. M. Iterative Synthesis of Oligo[n]rotaxanes in Excellent Yield. J. Am. Chem. Soc. 2016, 138, 16329-16336.

(xvii ) Lewis, J. E. M.; Bordoli, R. J.; Denis, M.; Fletcher, C. J.; Galli, M.; Neal, E. A.; Rochette, E. M.; Goldup, S. M. High Yielding Synthesis of 2,2'-Bipyridine Macrocycles, Versatile Intermediates in the Synthesis of Rotaxanes. Chem. Sci. 2016, 7, 3154-3161.

${ }^{(x v i i i}$ ) Selected examples: (a) Albrecht-Gary, A. M.; Saad, Z.; Dietrich-Buchecker, C. O.; Sauvage, J. P., Interlocked Macrocyclic Ligands: A Kinetic Catenand Effect in Copper(I) Complexes. J. Am. Chem. Soc. 1985, 107, 3205-3209. (b) Leigh, D. A.; Lusby, P. J.; Slawin, A. M.; Walker, D. B., Rare and Diverse Binding Modes Introduced through Mechanical Bonding. Angew. Chem. Int. Ed. 2005, 44, $4557-$ 4564. (c) Cirulli, M.; Kaur, A.; Lewis, J. E. M.; Zhang, Z.; Kitchen, J. A.; Goldup S. M.; Roessler, M. M. Rotaxane-Based Transition Metal Complexes: Effect of the Mechanical Bond on Structure and Electronic Properties. J. Am. Chem. Soc. 2019, 141 (2), 879-889.

(xix) Deppmeier, P. E.; Driessen, B. J.; Hehre, A. J.; Hehre, W. J.; Johnson, T. S.; Ohlinger, J. A.; Klunzinger, S. Spartan 18, build 1.3.0 (Feb 19 2019), Wavefunction Inc., 2019," 2019. 